\title{
Does rosmarinic acid underestimate as an experimental cardiovascular drug? ${ }^{1}$
}

\author{
Seria o ácido rosmarínico subestimado como droga cardiovascular experimental?
}

\begin{abstract}
Luciana Garros Ferreira ${ }^{\mathrm{I}}$, Andrea Carla Celotto ${ }^{\mathrm{II}}$, Verena Kise Capellini ${ }^{\mathrm{II}}$, Agnes Afrodite Sumarelli Albuquerque ${ }^{\mathrm{IV}}$, Tales Rubens de Nadaiv, Marco Tulio Menezes de CarvalhoVI, Paulo Roberto Barbosa Evora ${ }^{\text {VII }}$

IFellow Master degree, Postgraduate Program in Medical Surgical Clinic from the Department of Surgery and Anatomy, Ribeirão Preto Faculty of Medicine, University of São Paulo (FMRP-USP). Ribeirão Preto - SP, Brazil. Acquisition and interpretation of data, collection of study information, manuscript writing.

IIPhD, Postgraduate Program in Medical Surgical Clinic from the Department of Surgery and Anatomy, Ribeirão Preto Faculty of Medicine, University of São Paulo (FMRP-USP). Ribeirão Preto - SP, Brazil. Acquisition and interpretation of data, collection of study information.

IIIPhD, Postgraduate Program in Medical Surgical Clinic from the Department of Surgery and Anatomy, Ribeirão Preto Faculty of Medicine, University of São Paulo (FMRP-USP). Ribeirão Preto - SP, Brazil. Acquisition and interpretation of data, collection of study information.

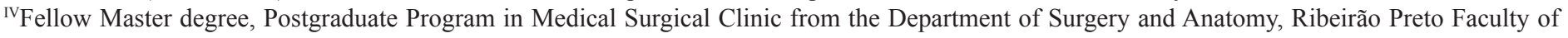
Medicine, University of São Paulo (FMRP-USP). Ribeirão Preto - SP, Brazil. Acquisition and interpretation of data, collection of study information, manuscript writing.

${ }^{\vee}$ MD, Postgraduate Program in Medical Surgical Clinic from the Department of Surgery and Anatomy, Ribeirão Preto Faculty of Medicine, University of São Paulo (FMRP-USP). Ribeirão Preto - SP, Brazil. Acquisition and interpretation of data, collection of study information.

${ }^{V I}$ Fellow Master degree, Postgraduate Program in Medical Surgical Clinic from the Department of Surgery and Anatomy, Ribeirão Preto Faculty of Medicine, University of São Paulo (FMRP-USP). Ribeirão Preto - SP, Brazil. Acquisition, collection of study information.

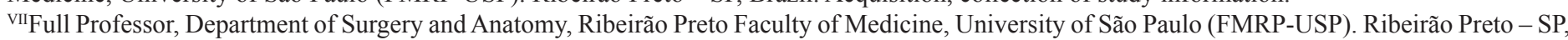
Brazil. Intellectual and scientific content of the study, supervised all phases, manuscript writing.
\end{abstract}

\begin{abstract}
PURPOSE: The rationale of the present review is to analize the activity of Rosmarinus officinalis in the the cardiovascular system METHODS: A MEDLINE database search (from January 1970 to December 2011) using only rosmarinic acid as searched term. RESULTS: The references search revealed 509 references about rosmarinic acid in 40 years (the first reference is from 1970). There is a powerful prevalence of antioxidant and cancer studies. Other diseases are few cited, as inflammation, brain (Alzheimer and Parkinson disease) and, memory; allergy; diabetes; atherosclerosis, and; hypertension. It is necessary to consider the complete absence of studies on coronary artery disease, myocardial ischemia, heart failure or ischemia/reperfusion injury.
\end{abstract}

CONCLUSION: Rosmarinic acid is underestimated as an experimental cardiovascular drug and deserves more attention.

Key words: Rosmarinus officinalis. Polyphenols. Cardiovascular diseases.

\section{RESUMO}

OBJETIVO: A justificativa da revisão é analisar a atividade de Rosmarinus officinalis no sistema cardiovascular

MÉTODOS: Uma busca de banco de dados MEDLINE (de janeiro de 1970 a dezembro de 2011), utilizando apenas o ácido rosmarínico como termo pesquisado.

RESULTADOS: A busca referências revelou 509 referências sobre o ácido rosmarínico em 40 anos (a primeira referência é de 1970). Há uma prevalência poderoso antioxidante e estudos do câncer. Outras doenças são citados alguns, como o cérebro, inflamação (de Alzheimer e doença de Parkinson) e, a memória, hipertensão, alergia, diabetes, aterosclerose, e. É necessário ter em conta a ausência completa de estudos sobre a doença de artéria coronária, isquemia do miocárdio, insuficiência cardíaca ou isquemia / lesão de reperfusão. CONCLUSÃO: O ácido rosmarínico é subestimado como uma droga experimental cardiovascular e merece mais atenção.

Descritores: Rosmarinus officinalis. Polyphenols. Doenças cardiovasculares. 


\section{Introduction}

Rosmarinus officialis is popularly known in Brazil as rosemary ${ }^{1}$. The presence of rosmarinic acid (RA) in medicinal plants, herbs and spices, has been generated healthy and beneficial effects. Among these were several RA biological activities, including antioxidant, astringent, anti-inflammatory, antimicrobial, antiangiogenic, antiviral, antirheumatic, antiallergic, antidepressant, antidiabetic, and antitumor ${ }^{2-13}$. However, reports on its activity in the cardiovascular system are scarce.

\section{Methods}

A MEDLINE database search (from January 1970 to December 2011) using only rosmarinic acid as searched term.

\section{Results}

AMEDLINE database search (until December 2011shows 509 references about rosmarinic acid in 40 years (the first reference is from 1970) (Figure 1). The interest for the phytoterapic increased in the last decade. There is a powerful prevalence of antioxidant (374 references) and cancer (33 references) studies. Other subjects are limited: inflammation (23 references); brain (Alzheimer disease, Parkinson disease, memory) (18 references); allergy ( 8 references); diabetes (11 references); atherosclerosis (5 references), hypertension (4 references) and sepsis ( 2 references). It is necessary to view the complete absence of studies on coronary artery disease, myocardial ischemia, heart failure or ischemia/ reperfusion injury (Figure 2). This is the rationale of the present review.

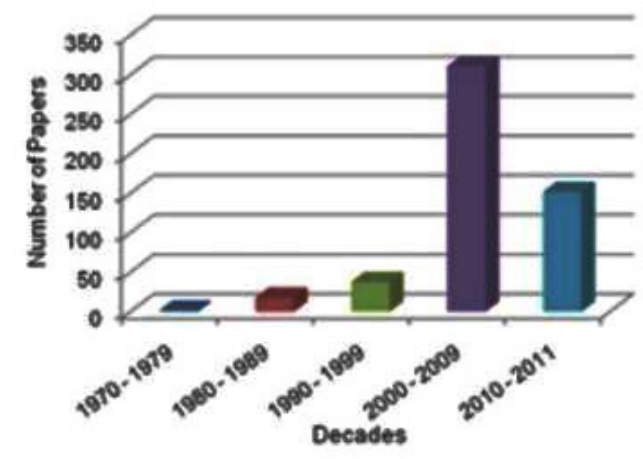

FIGURE 1 - Decade-course of rosmarinic acid MEDLINE references.

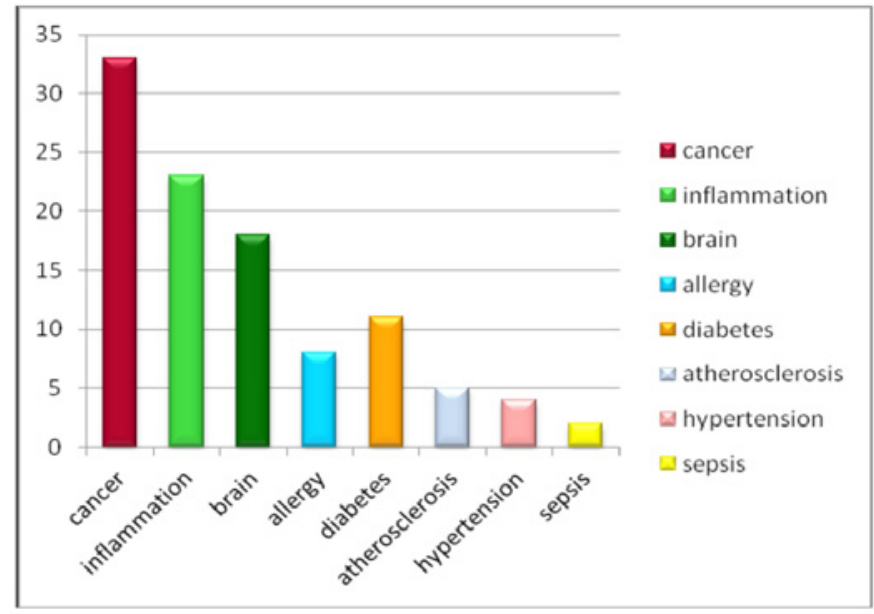

FIGURE 2 - Absolute numbers of rosmarinic acid MEDLINE references.

\section{Discussion}

\section{Rosmarinic acid pharmacological properties}

Extract of rosemary relaxes smooth muscles of the trachea and intestine and has choleretic, hepatoprotective and antitumerogenic activity. $\mathrm{RA}, \mathrm{C}_{18} \mathrm{H}_{16} \mathrm{O}_{8}$, is the most prominent constituents of rosemary (Figure 3). Structurally, the RA is an ester of caffeic acid and lactic acid 3.4 dihidroxifenil. These acids are widely distributed in the vegetable kingdom. Biogenetic studies from Mentha species (mint) showed that two aromatic amino acids, phenylalanine and tyrosine are incorporated into the RA. Part of caffeic acid, interestingly, is formed by part of the phenylalanine and 3.4 dihidroxifenil lactic acid is formed by tyrosine. These compounds have an antioxidant effect. RA is easily absorbed from the gastrointestinal tract and skin. It increases the production of prostaglandin E2, reduces the production of leukotriene B4 in human polymorphonuclear leucocytes, and inhibits the complement system. It is concluded that rosemary and its constituents, especially caffeic acid derivatives such as rosmarinic acid, have a therapeutic potential in treatment or prevention of bronchial asthma, spasmogenic disorders, peptic ulcer, inflammatory diseases, hepatotoxicity, atherosclerosis, ischaemic heart disease, cataract, cancer and reduced sperm motility $2,5,14,15$.<smiles>O=C(/C=C/c1ccc(O)c(O)c1)OC(Cc1ccc(O)c(O)c1)C(=O)O</smiles>

FIGURE 3 - Rosamarinic acid formula. 


\section{Rosmarinic acid and cardiovascular diseases}

\section{Cardiomyopathy}

The study used melaton to induce rat cardiopathology. The administration of luteolin and echinochrome provided to $100 \%$ animal probability of survival. At the same time, mitochondrial apparatus of cardiomyocytes was characterized by the normal parameter, therefore, given preparations have provided of a protective effect at cardiomyocytes level. However, similar activities for rosmarinic acid have not shown ${ }^{16}$.

Other study was undertaken to investigate the inhibitory effect of RA on adriamycin (ADR)-induced apoptosis in $\mathrm{H} 9 \mathrm{c} 2$ cardiac muscle cells at a mechanistic level. In vitro, ADR significantly decreased the viabilities of $\mathrm{H} 9 \mathrm{c} 2$ cells, and this was accompanied by apoptotic features, such as a change in nuclear morphology and caspase protease activation. RA was found to inhibit these apoptotic characteristics by reducing intracellular reactive oxygen species (ROS) generation and by recovering the mitochondria membrane potential. Results of this exhaustive study suggested that RA can inhibit ADR-induced apoptosis, proposing that RA should be viewed as a potential chemotherapeutic that inhibits cardiotoxicity in ADR-exposed patients ${ }^{17}$.

Inside this same research program, the cardioprotective effect of Prunella vulgaris ethylacetate fraction (PVEF) and its constituent RA was evaluated on isolated rat cardiomyocytes subjected to doxorubicin-induced oxidative stress. The cytoprotectivities effect of PVEF and RA were concentrationdependent in the range of 0.005 to $0.05 \mathrm{mg} / \mathrm{ml}$ and the effect of PVEF correlated with the RA content. As found, the mechanism of the cardioprotective effects of the extract is most probably linked with the antioxidant capacity due to its high content of phenolic acids, mainly RA. It's associated with scavenging of free radicals formed during application of doxorubicin and inhibition of lipid peroxidation of membrane systems as mitochondria, which positively influences the energy capacity of cardiomyocytes. Dexrazoxan, used as a positive control, was less effective than PVEF or $\mathrm{RA}^{18}$. In addition, chemoprotective effect of plant phenolics (caffeic, chlorogenic and rosmarinic acids) against anthracycline-induced toxicity on rat cardiomyocytes were reported ${ }^{19}$.

\section{Rosmarinic acid, dislipidemia and atherosclerosis}

Exogenous molecules from dietary sources such as polyphenols are highly effective in preventing the alteration of lipid membranes by oxidative stress. Among the polyphenols, the RA is an important compound studied. One full investigation attested the effectiveness of RA in preventing lipid peroxidation and in interacting with lipids. The study of transferred lipid/RA monolayers by atomic force microscopy revealed that $1 \mathrm{~mol} \%$ of $\mathrm{RA}$, in the membrane, was not sufficient to alter the membrane structure at the nanoscale. By fluorescence, the investigators observed no significant modification of membrane permeability and fluidity caused by the interaction with RA. They prepared 1,2-dilinoleoyl-sn-glycero-3-phosphocholine

(DLPC)/RA vesicles that evidenced, for the first time that up to $1 \mathrm{~mol} \%$ of RA inserts spontaneously in the membrane, which is strong enough to prevent lipid peroxidation without any noticeable alteration of the membrane structure due to RA insertion ${ }^{13}$.

There are suggestive evidences that oxidatively modified low-density lipoprotein (LDL) is atherogenic, and that atherosclerosis can be attenuated by natural antioxidants, which inhibit LDL oxidation. Natural antioxidants combinations exist in nature aimed one study to determine the in vitro and in vivo effects of tomato lycopene, alone or in combination with other natural antioxidants, on LDL oxidation. The polyphenols glabridin (derived from licorice), rosmarinic acid or carnosic acid (derived from rosemary), as well as garlic (which contains a blend of natural antioxidants) inhibited LDL oxidation in a dose-dependent manner. When lycopene was added to LDL in association with these polyphenols, synergistic antioxidative effects were obtained against LDL oxidation induced either by copper ions or the radical generator 2',2'-Azobis 2-amidino propane hydrochloride (AAPH). After administering a fatty meal containing lycopene in the form of tomato oleoresin, postprandial LDL isolated 5 hour after meal consumption exhibited a significant reduced susceptibility to oxidation by $21 \%$. The study concluded that lycopene acts synergistically, as an effective antioxidant against LDL oxidation, with some natural antioxidants such as vitamin E, the flavonoid glabridin, the phenolics rosmarinic acid and carnosic acid, and garlic. These observations suggest a greater antiatherogenic property to a combination of different natural antioxidants over that of an individual one ${ }^{3}$.

\section{Rosmarinic acid and metabolic syndrome}

One study investigated whether RA supplementation prevents cardiac abnormalities and hypertension in fructose-fed rats (FFR), as the RA has insulin-sensitizing and antioxidant effects in high fructose-fed model of insulin resistance. RA supplementation to FFR significantly improved insulin sensitivity, 
reduced lipid levels, oxidative damage, and the expression of p22phox subunit of nicotinamide adenine dinucleotide phosphate reduced oxidase, and prevented cardiac hypertrophy. The blood pressure was also lowered by RA through a decrease in endothelin-1 and angiotensin-converting enzyme activity and increase in nitric oxide levels. Histology revealed a decrease in myocardial damage, in RA-supplemented FFR. From these findings, it is suggested that RA acts as a vasoactive substance and a cardioprotector through its antioxidant effects. Thus, RA may be useful in reducing the cardiovascular risk associated with $\mathrm{IR}^{20}$.

\section{Rosmarinic acid and hypertension}

Although there are currently large selections of antihypertensive agents available for the treatment of hypertension, cardiovascular problems related to this disease continue to affect millions of people worldwide. Currently, the use of medicinal plants as a therapeutic option in various diseases, among them cardiovascular diseases, has gained ground. This is due to several factors, including the high cost of manufactured drugs, although the government is providing some anti-hypertensive, lack of public access to healthcare and pharmaceutical industries, the opportunity to make compounds with pharmacological activities often superior to current medications and a tendency for consumers to use natural products. Thus, the discovery of new substances with anti-hypertensive medication, low cost and rare adverse effects is still an attractive and beneficial aspect for clinical use. However, difficulties are encountered for this purpose including the possibility of an experimental model, obtaining standardized extracts and the difficulty of obtaining, isolation and identification of active substances.

High-blood pressure (HBP) is a common cardiovascular disease that affects millions of people worldwide. There are several ways to treat hypertension, such as the use of inhibitors of angiotensin-converting enzyme (ACE). In recent years, it has been demonstrated in vitro the inhibitory effect of some plant species on ACE and RA is a prominent constituent of these species ${ }^{21}$. However, literature reports about its activity in the cardiovascular system are scarce.

The RA effect on BP could be related to inhibition and/ or modulation of ACE, as shown by Li et al..$^{21}$ and Karthik et al. $(2011)^{20}$, or the endothelium-dependent vasodilator effect of RA as reported by Ersoy et al. $(2008)^{22}$. The mechanisms involved in this relaxing effect remain unknown. Nevertheless, this effect was attributed to the fact that RA is a polyphenolic compound and, according to recent studies, these compounds would have vasodilator activity, through activation of NO pathway, endothelium-dependent hyperpolarizing factor (EDHF) and prostacyclin $\left(\mathrm{PGI}_{2}\right)^{22,23}$. In addition, other possible mechanisms may be involved in this response, as in endothelial cells, which increased levels of $\mathrm{Ca}^{+2}$ and activation of the PI3-kinase/Akt lead to a rapid and sustained activation of the enzyme nitric oxide synthase (NOS) and hyperpolarization ${ }^{22}$. A third suggested mechanism is the RA antioxidant effect. The RA presents itself as a potent inhibitor of $\bullet \mathrm{O}_{2}{ }^{-}$and an effective protector of tissue damage caused by peroxynitrite ${ }^{20}$.

\section{Conclusions}

As RA is, nowadays, investigated in our laboratory, we carried out the presented MEDLINE search, and, it was a surprise the number of references about cardiovascular diseases. So we planned to share our uncertainty illustrated on the text title: does rosmarinic acid underestimate as a cardiovascular current drug? We trust that it is because we are getting satisfactory results on rat models of hypertension. In an overview, we hypothesize that AR deserves more experimental and clinical research in the cardiovascular milieu.

\section{References}

1. Scarpati ML, Oriente G. Isolamento e costituzione dell'acido rosmarinico (dal rosmarinus off.). Ricerca Sci. 1958;28:2329-33.

2. Parnham MJ, Kesselring K. Rosmarinic acid. Drugs Future. 1985;10:756-7.

3. Fuhrman B, Volkova N, Rosenblat M, Aviram M. Lycopene synergistically inhibits LDL oxidation in combination with vitamin E, glabridin, rosmarinic acid, carnosic acid, or garlic. Antioxid Redox Signal. 2000;2:491-506.

4. Takeda H, Tsuji M. Inazu M, Egashira T, Matsumiya T. Rosmarinic acid and caffeic acid produce antidepressive-like effect in the forced swimming test in mice. Eur J Pharmacol. 2002;449:261-7.

5. Petersen M, Simmonds MS. Rosmarinic acid. Phytochemistry. 2003;62:121-5.

6. Osakabe N, Yasuda A, Natsume M, Yoshikawa T. Rosmarinic acid inhibits epidermal inflammatory responses: anticarcinogenic effect of Perilla frutescens extract in the murine two-stage skin model. Carcinogenesis. 2004;25:549-57.

7. Takano H, Osakabe N, Sanbongi C, Yanagisawa R, Inoue K, Yasuda A, Natsume M, Baba S, Ichiishi E, Yoshikawa T. Extract of Perilla frutescens enriched for rosmarinic acid, a polyphenolic phytochemical, inhibits seasonal allergic rhinoconjunctivitis in humans. Exp Biol Med (Maywood). 2004;229:247-54.

8. Huang SS, Zheng RL. Rosmarinic acid inhibits angiogenesis and its mechanism of action in vitro. Cancer Lett. 2006;239:271-80.

9. Koukoulitsa C, Zika C, Geromichalos GD, Demopoulos VJ, Skaltsa $\mathrm{H}$. Evaluation of aldose reductase inhibition and docking studies of some secondary metabolites, isolated from Origanum vulgare L. ssp. hirtum. Bioorg Med Chem. 2006;14:1653-9.

10. Dubois M, Bailly F Mbemba G, Mouscadet JF, Debyser Z, Witvrouw 
M, Cotelle P. Reaction of rosmarinic acid with nitrite ions in acidic conditions: discovery of nitro- and dinitrorosmarinic acids as new anti-HIV-1 agents. J Med Chem. 2008;51:2575-9.

11. Furtado MA, De Almeida LC, Furtado RA, Cunha WR, Tavares DC Antimutagenicity of rosmarinic acid in Swiss mice evaluated by the micronucleus assay. Mutat Res. 2008;657:150-4.

12. Sa CM, Ramos AA, Azevedo MF, Lima CF, Fernandes-Ferreira M, Pereira-Wilson C. Sage tea drinking improves lipid profile and antioxidant defences in humans. Int J Mol Sci. 2009;10:3937-50.

13. Fadel $\mathrm{O}$, El Kirat $\mathrm{K}$, Morandat $\mathrm{S}$. The natural antioxidant rosmarinic acid spontaneously penetrates membranes to inhibit lipid peroxidation in situ. Biochim Biophys Acta. 2011;1808:2973-80.

14. Ellis BE, Towers GH. Biogenesis of rosmarinic acid in Mentha. Biochem J. 1970;118:291-7.

15. al-Sereiti MR, Abu-Amer KM, Sen P. Pharmacology of rosemary (Rosmarinus officinalis Linn.) and its therapeutic potentials. Indian J Exp Biol. 1999;37:124-30.

16. Tsibul'skiı̌ AV, Popov AM, Artiukov AA, Kostetskiǐ ÉIa, Krivoshapko ON, Mazerka AN, Kozlovskaia ÉP. The comparative study of the medical action of lyuteolin, rosmarinic acid and echinochrom A at experimental stress-induced cardiopathology. Biomed Khim. 2011;57:314-25.

17. Kim DS, Kim HR, Woo ER, Hong ST, Chae HJ, Chae SW. Inhibitory effects of rosmarinic acid on adriamycin-induced apoptosis in H9c2 cardiac muscle cells by inhibiting reactive oxygen species and the activations of c-Jun N-terminal kinase and extracellular signalregulated kinase. Biochem Pharmacol. 2005;70:1066-78

18. Psotová J, Chlopcíková S, Miketová P, Simánek V. Cytoprotectivity of Prunella vulgaris on doxorubicin-treated rat cardiomyocytes. Fitoterapia. 2005;76:556-61.

19. Chlopcíková S, Psotová J, Miketová P, Sousek J, Lichnovský V, Simánek V. Chemoprotective effect of plant phenolics against anthracycline-induced toxicity on rat cardiomyocytes. Part II. caffeic, chlorogenic and rosmarinic acids. Phytother Res. 2004;18:408-13.

20. Karthik D, Viswanathan P, Anuradha CV. Administration of rosmarinic acid reduces cardiopathology and blood pressure through inhibition of p22phox NADPH oxidase in fructose-fed hypertensive rats. J Cardiovasc Pharmacol. 2011;58:514-21.

21. Li QL, Li BG, Zhang Y, Gao XP, Li CQ, Zhang GL. Three angiotensin-converting enzyme inhibitors from Rabdosia coetsa. Phytomedicine. 2008;15:386-8.

22. Ersoy S, Orhan I, Turan NN, Sahan G, Ark M, Tosun F. Endotheliumdependent induction of vasorelaxation by Melissa officinalis L. ssp. officinalis in rat isolated thoracic aorta. Phytomedicine. 2008; 15:1087-92.

23. Fernandes L, Fortes ZB, Casarini DE, Nigro D, Tostes RC, Santos RA, de Carvalho MH. Role of PGI2 and effects of ACE inhibition on the bradykinin potentiation by angiotensin-(1-7) in resistance vessels of SHR. Regul Pept. 2005;127:183-9.

\section{Acknowledgements}

This study was partially supported by Fundação de Amparo à Pesquisa do Estado de São Paulo (FAPESP) and Fundação de Apoio ao Ensino, Pesquisa e Assistência do Hospital das Clínicas da Faculdade de Medicina de Ribeirão Preto da Universidade de São Paulo (FAEPA HCFMRP/USP), SP, Brazil.

\section{Correspondence:}

Paulo Roberto B. Evora

Rua Rui Barbosa, 367/15,

14015-120 Ribeirão Preto - SP Brasil

Tel./Fax: (55 16)3602-2497

prbevora@fmrp.usp.br

Conflict of interest: none

Financial sources: FAPESP, FAEPA, CNPq

${ }^{1}$ Research performed at Laboratory of Endothelial Function, Department of Surgery and Anatomy, Ribeirão Preto Faculty of Medicine, University of São Paulo, Brazil. 